\title{
An AHP Approach for Ranking Critical Success Factors of Customers Experience in Iranian Banks from Managers' Viewpoint
}

\author{
Fariddedin Allameh Haery ${ }^{1}$, Hasan Ghorbani ${ }^{1} \&$ Ali Asghar Farahmand ${ }^{1}$ \\ ${ }^{1}$ Islamic Azad University, Mobarakeh, Isfahan, Iran \\ Correspondence: Fariddedin Allameh Haery, Department of Management, Mobarakeh Branch, Islamic Azad \\ University, Mobarakeh, Isfahan, Iran. Tel: 98-311-666-2096. E-mail: farid_ahaery@yahoo.com
}

$\begin{array}{ll}\text { Received: September 17, } 2013 & \text { Accepted: October 15, } 2013 \quad \text { Online Published: January 22, } 2014 \\ \text { doi:10.5539/ijms.v6n1p168 } & \text { URL: http://dx.doi.org/10.5539/ijms.v6n1p168 }\end{array}$

\begin{abstract}
Nowadays, customer experience is considered as a critical factor in growth cycle of each business. These days only those organizations that their main focus is fulfilling customer's demands and desires with maximum quality can be succeed. The main purpose of this study is identifying and prioritizing critical success factors from perspective of bank's managers and experts. Considering these factors as key success factors can improve customer experience in banking services and help the banks to provide more favorable experience for customer. The statistical population consist of manager and customer of Refah bank in Isfahan city. Because the number of managers was limited census method has been used to select appropriate number of manager and expert. For data analyzing, Analytic Hierarchy Process (AHP) through pair-wise comparison of factors and sub-factors has been applied by using Expert Choice software. The results suggest that "behavioral experience" is the most important factor in designing customer experience. So, behavioral experience has the most influence on critical success factors at Refah bank. Cognitive aspect possesses the second priority and "affective experience" possesses the lowest priority among all the other factors. By calculating inconsistency rate of pair-wise comparison matrix, consistency of these factors is also acceptable. In addition, considering the result sub-criteria of "employees" and "service process" possess the first and second priority respectively between fourteen sub-criteria of critical success factors.
\end{abstract}

Keywords: customer experience, critical success factors, banking, analytic hierarchy process (AHP), bank's managers and experts

\section{Introduction}

In this era, there is a global trend to create desirable experience for customers .lots of companies in most industries are performing studies, evaluation and directing appropriate strategies in order to create favorable experience and making plan with the purpose of developing powerful relationship with their customers (Banasiewicz, 2005). Customer experience is an organizational concept that influenced by variety of factors inside and outside of organization. Accurate understanding of these factors and determining the degree of their influence, has significant importance to assist manager in order to make right decisions. Studies indicate that considerable investment is required to attract new customers compared with maintaining current customers. These finding suggest that attracting a new customer is six to eight time costlier than keeping existing customers (Duncan \& Moriarty, 1997). These days the importance of service section is incrementally increasing around the world (Tseng et al, 1999). Services are offering in different area such as hotel management, tourism, banking and insurance, telecommunications and many other fields, but customer interaction with service companies is different in all the cases. This kind of manner is depends on type of service process and degree of contact with the customer (Lovelock, 1996). Due to increase in specific and diversify needs of customers and intense of competition between companies in order to make goods and services homogeneous, empirical aspect of servicing has been central to the customer attention (Liu \& Liu, 2008).

In banking industry, most of managers perceived the number of customer as loyal customers, but actually the number of clients does not indicates that they are royal customers, the reason is many of bank's accounts are unused or just have a few operations (Brauer, 2005). In fact despite that customers are dissatisfied or have had a bad experience with banks service offering process, they have a little tendency to change the service organization (Rahman, 2006). In such a situation, maintenance of customer implies forced loyalty to the bank to avoid paying 
the changing costs (Licata \& Chakraborty, 2009). So bank director most work carefully to promote customer's experiences. On the other hand, organizational resources are limited and if a manager is looking for making plan to keep the customers, he/she must allocate these limited resources with attention to such factors that influence on customer experience and with considering the importance of each factor. In this regard, present study aims to identify and prioritize the critical success factor of customer experience in Refah Bank by using analytic hierarchical process method.

\subsection{Relevant Scholarship}

Previously Garg et al (2012) attempted to identify and prioritize the critical success factors of customer experience through reviewing literature and interviewing with banking experts and by use of AHP methodology and with the purpose of improving customer experiences. Results of their study suggest that elements such as facilities, convenience, employee, functional elements and physical equipment have the most important from the perspective of customers. Also Sipahi and Timor (2010) stated that using AHP methodology has increased incrementally in the years 2005 to 2009. Although they believe Analytic Network Process (ANP) will be flourished more in future. They collaborations results suggest that AHP methodology has been used in areas such as finance and banking. In addition Korhonen et al. (2006) proposed a structure based on creating alliance between bank and insurance companies from perspective of customers in their article. They suggest Seven criteria were introduced for the evaluation of six alternative structure models for such alliances of banks and insurance companies which eventually by using AHP method it was determined that simple marketing agreement was preferred more in compare with other factors.

\subsection{Literature Review}

\subsubsection{Critical Success Factor}

Critical success factors are kind of indicators that manager must identify and control them. Recognizing these factors can contribute to the success of organization and not to providing them can increase the probability of organizational failure. These critical success factors do exist and are not created and must be identified and discovered at different levels of organization. The most important sources of extracting these industrial factors are organizations and also managers in deferent levels of company. By identifying critical success factors, beneficial and essential information system can be designed and as a result the organizational success can be accomplished (Shakeri, 2007). The idea of critical success factor was first proposed by Ronald Nil at 1960s and after one decade this concept was extended by Rockart and it has been used to facilitate the execution of strategies in business and project since then. The simple and approached-based definition of "critical success factor" based on Rockart idea suggests: "Those few areas of activities in which favorable results will ensure successfulness of competitive performance of individuals, departments or organizations". Critical success factors are strongly related to strategic goals and mission of a business or project. To identify possible critical success factors, the missions and goals must be evaluated to figure out which areas in business must be considered more.

\subsubsection{Customer Experience}

Today, the term of "customer experience" has become a considerable term in business literature and most of organizations aim to promote this concept to gain competitive advantages over their competitors. Customer experience is complex of perceptions, emotions and thoughts that is result of all tangible or intangible impacts of an organization or a company's activities (Garg et al., 2012). Trying to define customer experience is more difficult than what is thought to be. The main problem is the recognition of this point that, whether customer experience is a behavioral variable or an attitudinal variable (Duffy, 1998)? Indeed, essence of customers' behavior plays important rule in experiences that they get.

A customer is not just the buyer of service or product which company offers but also he/she buys experience from company (Bateson, 1995). Researches about customer experience are growing increasingly, but existing studies are mostly focus on empirical concept of customer experiences. Articles related to structure measuring that assist managers to analyze the critical success factors in order to provide better customer experience are limited (Gentile et al., 2007; Meyer \& Schwager, 2007; Verhoef et al., 2009). Using the criteria "customer desired experience" as a representative of loyalty measure is so common, because it is assumed that customer experience has a positive effect on buying intention.

Five dimensions which are used to assess customer experience are: sensory experience, affective, cognitive, behavioral and relational experience. These dimensions also include some sub-dimension. Sensual experience refers to aesthetic aspect of a product or service that can be precept by The Five Senses. Affective dimension implies those stimulus that affect on inner feeling of customers. Cognitive aspect is totally refers to cognitive 
performance and mental process of one person's mind. Another factor that affects customer experience is behavioral experience which considers customer's physical experiences, interactions and life styles. The last dimension, relational aspect, is related to interactions between customers and customers or customer with bank (Smith, 1999).

\subsubsection{Critical Success Factor and Customer Experience}

In order to create a favorable experience for customer in the marketing field, it is essential to investigate different factors of experience in diversify aspect and dimension. In addition, this concept has 100 percent influence on loyalty and lead to uncertainty and indicates that customer can be loyal to two or three brands name in each class of services (Duffy, 1998). Studies indicate that it is simplistic to assume that customers with unfavorable experience are missed but customer with favorable experience will survive. Actually Rychheld has shown that regardless of favorable or unfavorable experience, customers will drop out. Again he proposed that most of customers that are satisfied with a specific brand name would not purchase from that brand again. These types of manner are probably because of some influential variables such as choice, convenience, price and income. Based on Garg et al. (2012) critical success factors such as interaction with customer, employee's behavior, physical evidence and tangibles, customer convenience, quick operation and visual and aesthetic elements both in inner space and internet (virtual space) and by considering other important factors which were identified in this study, promotion of customer experience and eventually the loyalty of customers can be obtained.

So it seems that by regarding attitudinal and behavioral criteria simultaneously and strengthen both categories, we will be able to improve customer experience about bank and its services and increase their loyalty to the bank.

\subsection{Research Hypothesis}

In this respect, it is attempted to identify critical success factor at first and then, the priority and importance of this factors in customer experiences and loyalty will be determined. So the following hypothesizes are stated as:

H1: From perspective of banks' managers and experts there are some effective factors which impact on customer experiences

H2: From perspective of bank's managers and experts, the degree and priority of each factor's influence on customer experience is different

H3: sensual experience of critical success factor is an effective dimension in promotion of customer experience from perspective of bank's managers and experts.

H4: affective experience of critical success factor is an effective dimension in promotion of customer experience from perspective of bank's managers and experts.

H5: cognitive experience of critical success factor is an effective dimension in promotion of customer experience from perspective of bank's managers and experts.

H6: behavioral experience of critical success factor is an effective dimension in promotion of customer experience from perspective of bank's managers and experts.

H7: relational experience of critical success factor is an effective dimension in promotion of customer experience from perspective of bank's managers and experts.

\section{Method}

\subsection{Identifying Subsection}

This study attempts to identify factors that influence customer experience, determine the prioritization of these factors and also investigating the rule of these factors "sensual ,affective, cognitive, behavioral and relational dimensions "in improving customers experience from the view point of Refah bank's managers and experts. The questionnaire which is applied in AHP method required a special design which is different from common questionnaire and need pair-wise comparison to be performed. There are five main dimensions which evaluate critical success factors, it means that ten paired comparisons is needed. Each of this dimensions contain some sub-dimension which is equal to 14 sub-dimensions in the whole this factors and sub-factors have been chosen based on interviewing with experts and university professors and also based on Garg et al. (2012) works. Sub-criteria are as following:

The first element is Sensory experience which includes two sub-dimensions which are physical evidence like decoration and equipment of client hall and equipment and electronic facilities... and the other one is online aesthetic which refer to design and beauty of bank's website and its features. Second factor is affective 
experience which contains four sub-dimensions which are customization (like writing customer's asked sentences on present card and connecting the customer's accounts (dual-purpose account)...) in other word it is refer to customizing some part of bank's services in order to being compliance with customers need and desire to make them satisfied. Third sub-dimension is Online hedonic elements such as attractive menus and alternatives which motivate customer to search more, and the last one is value added which refers to a group of extra services which helps to create a unique and memorable emotions for customers. The other measure is cognitive experience which includes three sub-dimensions as convenience, marketing mix and online functional elements. Welfare facilities such as parking lot location, information counter, appropriate strategies and methods and existing of functional menu on bank's websites are the most important elements of this dimension. The other factor which influence on customer experience is behavioral aspect, this dimension include some sub-dimensions such as employee, special attention to knowledge, speed, respect the customer's time and finally service process. The last parameter proposed as interactions between customers and customers and customers and bank which called relational aspect. This measure contains two sub-dimensions which are customer interaction and presence of other customers.

\subsection{Participant (Subject) Characteristics}

In order to use AHP method for prioritizing, there is a need to gather and ask the expert's opinion based on pair-wise comparison, so managers and experts of Refah bank were asked to take part in survey as statistical population members.

\subsection{Sampling Procedures}

Since the population of managers and administrators was limited, census method has been applied to choose the number of sample's members.

\subsubsection{Sample Size}

Based on census method the number of 45 managers and experts of Refah bank were selected and the questionnaire delivered to them which all of the questionnaire were filled and received which means the response rate was 100 percent.

\subsubsection{Measures and Covariates}

As said before, we have applied analytic hierarchical process (AHP) to identify and prioritize the critical success factors. AHP is one of the most popular multi-criteria decision making (MCDM) method that has initially been introduced by L.Saati in the year of 1970. It deals with complex problems by fragmenting them into a hierarchical structure. The AHP is a decision support tool which can be used to solve complex decision problems. It uses a multi-level hierarchical structure of objectives, criteria, sub-criteria, and alternatives. This method can be applied when the decision making act is faced with multifaceted and multi-criteria decisions. Developed criteria can be both quantitative and qualitative. This method is based on pair-wise comparison and the decision maker starts the operation by forming the hierarchy tree. Hierarchy tree shows the levels of comparable under estimate variables and comparative alternatives and then a bunch of pair-wise comparison will be performed. These comparisons determine the weight of each factors in compared with another factors and eventually the logic of hierarchical process, integrate the obtained matrixes so that the optimal decision will be achieved. The steps of the AHP are as follows.

- Step1: Define and state the objectives of the complex and ambiguous problem clearly.

- Step2: The multifaceted problem is decomposed into a hierarchal structure with the help of group decision or survey technique. The hierarchal structure is divided into multiple levels. The top level hierarchy represents the goal of the problem. This goal is sub-divided into various criteria in the next level. The criteria are further divided into sub-criteria levels which highlight the details of the criteria. This decomposition of the hierarchy takes place until no more decomposition of sub-criteria is possible.

- Step3: The third stage in AHP is creation of the normalized matrices and defining the importance level of the factors. Normalized matrix is obtained by dividing the each column values of comparison matrix created at the second stage into the sum of related column separately. The value for each row is summed using normalized matrix and the average value of each is counted. The obtained value is the priority vector and it gives the importance level (rate) of the criteria on the row .

- Step4: The fourth stage in AHP is to determine whether the matrixes are consistent or not. The main purpose is to determine how much the importance values (relative priority) reflect the reality. In order to consider AHP valid, matrices must be consistent. In order to determine whether the matrix is consistent or not, 
the defined importance level for each factor at the third stage and the comparison matrix of related column created at the second stage are multiplied and summed and the rate vector is obtained. Consistency index (Consistency Index- I.I) is calculated as

$$
\text { I.I. }=\frac{\lambda_{\max }-n}{n-1}
$$

Where $\lambda_{\max }$ is the largest eigenvalue of pair-wise comparison matrix and $\mathrm{n}$ is the rank of the matrix and random index (I.R.) which is the I.I. of the matrices which are generated randomly. For different matrix size (n), the respective values of I.R. are depicted in Table 1. After that, Consistency Rate must be calculated in order to see whether decision maker was consistent during making comparison or not (Erbasi \& Parlakayya, 2012). Consistency ratio (I.R) is calculated with;

$$
I . R=\frac{I . I \cdot}{I . I \cdot R}
$$

\begin{tabular}{|c|c|c|c|c|c|c|c|c|c|c|}
\hline $\mathrm{n}$ & 1 & 2 & 3 & 4 & 5 & 6 & 7 & 8 & 9 & 10 \\
\hline I.I.R. & 0.0 & 0.0 & 0.58 & 0.9 & 1.12 & 1.24 & 1.32 & 1.41 & 1.45 & 1.45 \\
\hline
\end{tabular}

Table 1. I.R. of random matrix

Also for data collection a survey was conducted by use of questionnaire. In this way, respondents determine the most important factors and then specified degree of importance (priority) of selected factor based on a 9 point scale. Expert Choice software has been used in this study to analyze the gathered data which is professional software for analyzing hierarchical process and it is supported by Saaty the funder of analytic hierarchical process. Reliability of the questionnaire which compares under prioritize factors is largely depend on analytic hierarchical process's technique, which is estimated by inconsistency rate. Considering that the consistency rate is equal to 0.1 and under 0.1 , so it can be suggest that the questionnaire is reliable.

\subsubsection{Research Design}

In accordance with literature review and based on study's hypothesis an AHP model has been developed to evaluate the customer experience in bank. For this purpose the evaluation of customer experience is placed on the top of tree, Six dimensions of critical success factor are placed on second level which called criteria level and finally the sub-criteria dimensions placed on third level of hierarchy tree. Figure 1 illustrates the conceptual model of the research.

After forming the hierarchy tree based on AHP methodology, a questionnaire was made based on theoretical framework in order to collect the required data.

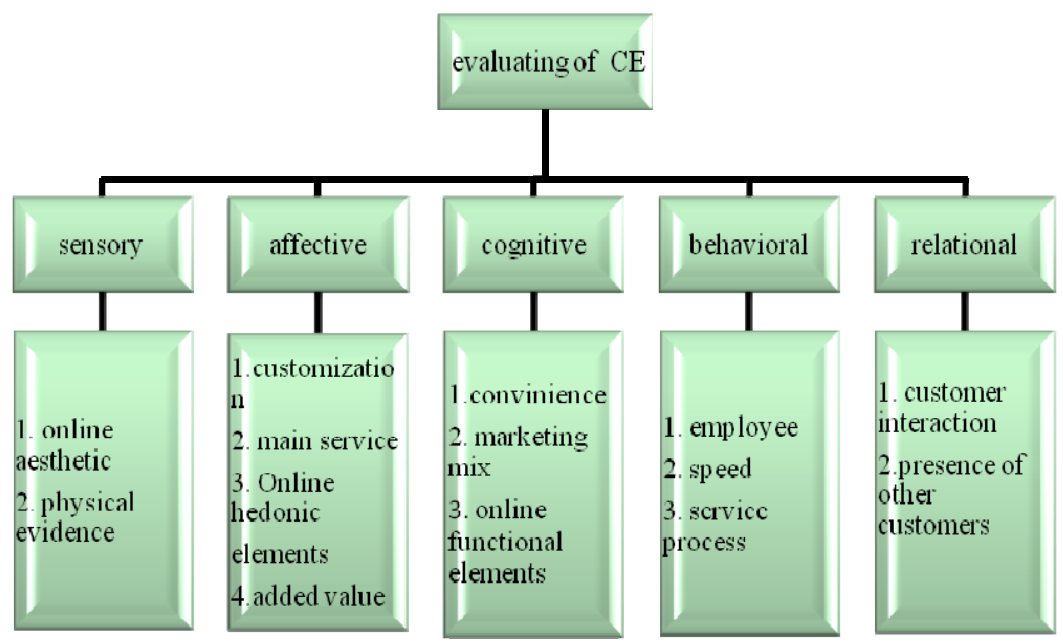

Figure 1. An AHP based model for the evaluation of customer experience in banking sector 


\section{Result}

As mentioned above, critical success factor have considerable importance on service offering and managers must consider this factor carefully in order to improve their service quality. In this study we attempted to identify the most important critical success factor and prioritize them. For this purpose the research's hypotheses were tested by analytic hierarchical process which used to prioritize the under investigate factors

\subsection{Statistics and Data Analysis}

In order to answer the first question of the study and determining the critical success factors some interviews were conducted and also primary literature of CSF were reviewed (e.g., Garg et al., 2012) and finally five dimension and 14 sub-dimension of CSF were identified.

In AHP analysis after creating pair-wise comparison matrix, weight of matrix's elements will be calculated. A pair-wise comparison matrix can be consistence or inconsistence, when the matrix is consistence weighting value calculation is simple and obtained by normalizing each column's elements. But practically, pair-wise comparison matrixes are often inconsistence and in this situation calculation of the weight is not simple. Here we use geometric mean method for calculating the weights. Results of CSF's pair-wise comparison are available on Table 2 .

Table 2. Pair-wise comparison of dimensions

\begin{tabular}{llllll}
\hline Main factors & sensory & affective & cognitive & behavioral & relational \\
\hline sensory & 1.000 & 0.681 & 0.187 & 0.203 & 0.963 \\
affective & 1.469 & 1.000 & 0.346 & 0.392 & 1.855 \\
cognitive & 5.344 & 2.893 & 1.000 & 0.570 & 3.633 \\
behavioral & 4.916 & 2.548 & 1.755 & 1.000 & 2.149 \\
relational & 1.038 & 0.539 & 0.275 & 0.465 & 1.000 \\
\hline
\end{tabular}

Results of investigating the second part questions and hypothesis are as following:

In general from the perspective of managers and experts, Behavioral experience with the weighting value of 0.361 possesses the highest priority. And cognitive aspect with the weighting value of 0.328 is placed on second position and finally sensory experience possesses the lowest weight $(0.078)$ and placed on last position. Rate of inconsistency was calculated as 0.1 which means the validity of comparisons are acceptable (table3). Also figure 2 addresses Priority-level of critical success factors.

Table 3. Composite priority weights for criteria and sub-criteria — data gathered from managers

\begin{tabular}{|c|c|c|c|c|}
\hline factor & $\begin{array}{l}\text { Local/global } \\
\text { weights }\end{array}$ & Sub-factor & Local weight & Global weight \\
\hline \multirow{2}{*}{ sensory } & \multirow{2}{*}{0.078} & Physical evidence & 0.737 & 0.058 \\
\hline & & Online aesthetic & 0.263 & 0.021 \\
\hline \multirow{4}{*}{ affective } & \multirow{4}{*}{0.134} & Customization & 0.182 & 0.024 \\
\hline & & Main service & 0.417 & 0.056 \\
\hline & & Online hedonic elements & 0.115 & 0.015 \\
\hline & & Value addition & 0.286 & 0.038 \\
\hline \multirow{3}{*}{ Cognitive } & \multirow{3}{*}{0.328} & Convenience & 0.406 & 0.133 \\
\hline & & Marketing mix & 0.390 & 0.128 \\
\hline & & Online functional elements & 0.203 & 0.067 \\
\hline \multirow{3}{*}{ Behavioral } & \multirow{3}{*}{0.361} & Employee & 0.406 & 0.147 \\
\hline & & Speed & 0.222 & 0.080 \\
\hline & & Service process & 0.372 & 0.134 \\
\hline \multirow{2}{*}{ Relational } & \multirow{2}{*}{0.099} & Customer interaction & 0.507 & 0.050 \\
\hline & & Presence of other customer & 0.493 & 0.049 \\
\hline
\end{tabular}

Results of calculating the priority of sub-criteria is as following: 
Prioritizing sub-dimension of sensory experience: According to calculated weights sub factors of physical evidence and online aesthetic with the weighting value of 0.737 and 0.263 respectively possess the highest priority

Prioritizing sub-dimension of affective experience: sub-factors of main service and added value accounting for 0.147 and 0.286 respectively have the most importance and possess first and second priorities. Customization and online hedonic elements with the weighting value of 0.182 and 0.115 are placed on third and fourth position respectively.

Prioritizing sub-dimension of cognitive experience: sub-criteria of convenience accounting for 0.406 possesses highest priority and marketing mix with the weighting value of 0.39 placed on second position and online functional element with the weighting value of 0.203 placed on third place.

Prioritizing sub-dimension of behavioral experience: sub-dimensions of employee, service process and speed with the weighting value of $0.406,0.372$ and 0.222 are ranked first to third respectively.

Prioritizing sub-dimension of relational experience: sub-dimensions of customer interaction and presence of other customer with the weighting value of 0.507 and 0.493 possess first and second priority respectively

Generally from the view point of managers, sub-dimensions of employee $(0.147)$, service process $(0.134)$, convenience (0.133), marketing mix (0.128), speed (0.08) and online functional element (0.067) possess the firs to sixth priority among all other factors. Also physical evidence $(0.058)$, main service $(0.056)$, customer interaction (0.05) and presence of other customer (0.049) have taken place on seventh till tenth priority. In addition total rate of inconsistency is equal to 0.03 which means the consistency of calculations in acceptable. Table 3 also addresses the weights of factors and sub-factors.

\subsection{Participant Flow}

Descriptive analysis has been used in order to analyze sample's demographic characteristics. Table 4 addresses the demographic characteristics of the respondents.

Table 4. demographic characteristic of sample's members

\begin{tabular}{llll}
\hline variable & Type & Frequency & percent \\
\hline Gender & Female & 7 & $16 \%$ \\
Age & male & 38 & $84 \%$ \\
& $25-35$ & 16 & $36 \%$ \\
Educational status & $36-45$ & 25 & $55 \%$ \\
& $46-60$ & 4 & $9 \%$ \\
\multirow{3}{*}{ Years of career } & Diploma & 6 & $13 \%$ \\
& Bachelor & 24 & $54 \%$ \\
& Masters & 15 & $33 \%$ \\
& $5-10$ & 3 & $7 \%$ \\
& $10-15$ & 19 & $42 \%$ \\
\hline
\end{tabular}

\section{Conclusion}

The main purpose of this study was identification and prioritizing the critical success factor of customer experience from perspective of managers of Refah bank in order to improve customers experience about bank. Results indicate that, behavioral and cognitive experiences have placed on first and second position. The other factor that has relative importance and possesses the third priority was affective experience. And also prioritizing sub-elements of CSF shows that the sub-dimensions of employee, service process and convenience possess higher priority compare with other sub-dimensions. According to results it can be proposed that the growth of the service economy puts more employees in contact with more customers and service companies most pay attention to behavioral and communicational aspects of service offering more than before. Employees are key stakeholders in value delivery and brand/supplier success, and they frequently represent the difference between positive experiences or negative experiences and whether customers stay or go. It has been found that employee commitment and advocacy behavior have a direct and profound relationship to the loyalty of customers, and also to corporate sales and profitability. According to Yoon et al (2004) "Customer's perceived service quality is one of the most important performances achieved by employees in the interaction between customers and the contact 
employee" Hence, the interaction between the customer and company employees can be conceived as the heart of a service (Bowers \& Martin, 2007). Furthermore, cognitive customer experience is an internal and subjective response of customers who have either direct or indirect contact with a company. Cognitive customer experience is a result of internal reflection that comes from the stimulus (Ruiping \& Yujuan, 2006). Hence, personal interaction is main factor that has a direct effect on cognitive customer experience (Chodchuang \& Sabri Haron, 2012). In this regard the banks managers must have a good business strategy designed to manage cognitive experience at all points of contact with its customers. In addition Delivering high quality products and services is a strategy which companies applied to compete with their rivals.Service quality determines customer satisfaction and service standards is defined by customers who receive services and judge about their quality based on their experiences and feeling. Service-based companies such as banks, hotels and restaurants put considerable effort into identifying and improving service quality in their businesses. All these companies have a common mission which is enhancing customer satisfaction. Right now service contribution to the economy is more than the half of total GNP of all countries around the world. In addition as the number and variety of service offering companies increase the demands and expectations of customer also enhance. So as Lin (2005) suggests, improving service quality is vital for company survival and progress. Gradual change in banking industry during last decade consider as a consequence of increase in between banks competition. Banking is kind of service offering which is in touch with customers a lot and beside what is presented, way of presentation and physical environment have considerable impact on customer awareness about bank's services. Today excellent service quality is a necessary condition of bank success. On the other hand customer's awareness about other banks services has increased and they no more accept every type of services. In such a situation the most appropriate strategy for banks is improving bank's services and increasing customer's optimal experiences

\section{References}

Banasiewicz, A. (2005). Loyalty Program Planning and Analytics. Journal of Consumer Marketing, 22(6), 332-339. http://dx.doi.org/10.1108/07363760510623920

Bowers, M. R., \& Martin, C. L. (2007). Trading places redux: employees as customers, customers as employees. Journal of Service Marketing, 21(2), 88-89. http://dx.doi.org/10.1108/08876040710737859

Brauer, H. (2005). Financial services customer loyalty. Finance Week, March, p. 49.

Chodchuang, S., \& Sabri, H. M. (2012). Cognitive customer experience of women shopper in personal interation in Thailand's department store: an examination of the influence of previous experience. Business Management Dynamics, 1(10), 10-21.

Duffy. D. L. (1998). Customer Loyalty Strategies. Journal of Consumer Marketing, 15(15), 435-448. http://dx.doi.org/10.1108/07363769810235910

Duncan. T., \& Moriarty, S. (1997). Driving Brand Value: Using Integrated Marketing to Manage Profitable Stakeholders Relationship. McGraw-Hill.

Garg, R., Rahman, Z., Qureshi, M., \& Kumar, I. (2012). Identifying and ranking critical success factors of customer experience in banks, An analytic hierarchy process (AHP) approach. Journal of Modeling in Management, 7(2), 201-220. http://dx.doi.org/10.1108/17465661211242813

Gentile, C., Spiller, N., \& Noci, G. (2007). How to sustain the customer experience: an overview of experience components that co-create value with the customer. European Management Journal, 25(5), 395-410. http://dx.doi.org/10.1016/j.emj.2007.08.005

Korhonen, P., Koskinen, L., \& Voutilainen, R. (2006). A Customer View on the Most Preferred Alliance Structure between Banks and Insurance Companies. Zeitschrift fur Betriebwirtschaft, 2, 139-164. http://dx.doi.org/10.1007/s11573-006-0003-2

Licata, J. W., \& Chakraborty, G. (2009). The effects of stake, satisfaction, and switching on true loyalty: a financial services study. International journal of bank marketing, 27(4), 252-69. http://dx.doi.org/10.1108/02652320910968340

Lin, W. B. (2005). An empirical of service quality model from the viewpoint of management. Expert systems with applications, 32(4), 364-375.

Liu, J. (2008). An empirical study on the relationship between service encounter, CE and repeat patronage intention in hotel industry, IEEE, 97(18), 210-424.

Lovelock, C. H. (1996). Services Marketing (3rd ed.). Englewood Cliffs, NJ: Prentice-Hall. 
Meyer, C., \& Schwager, A. (2007). Understanding customer experience. Harvard Business Review, 85(2), $116-26$.

Rahman, Z. (2006). Customer experience management - a case study of an Indian bank. Database Marketing \& Customer Strategy Management, 13(3), 203-21. http://dx.doi.org/10.1057/palgrave.dbm.3240298

Saaty, T. L. (1994). How to make a decision: the analytic hierarchy process. Interfaces, 24(6), 19-43. http://dx.doi.org/10.1287/inte.24.6.19

Sipahi, S., \& Timor, M. (2010). The analytic hierarchy process and analytic network process: an overview of applications. Management Decision, 48(5), 775-808.

Tseng, M. M., Qinhai, M., \& Su, C. (1999). Mapping customers' service experience for operations improvement. Business Process Management Journal, 5(1), 50-64. http://dx.doi.org/10.1108/14637159910249126

Verhoef, P. C., Lemon, K. N., Parasuraman, A., Roggeveen, A., Tsiros, M., \& Schlesinger, L. A. (2009). Customer experience creation: determinants, dynamics and management. Strategies Journal of Retailing, 85(1), 31-41. http://dx.doi.org/10.1016/j.jretai.2008.11.001

Yoon, M. H., Seo, J. H., \& Yoon, T. S. (2004). Effect of contact employee supports on critical employee responses and customer service evaluation. Journal of service Marketing, 18(5), $395-412$. http://dx.doi.org/10.1108/08876040410548311

\section{Copyrights}

Copyright for this article is retained by the author(s), with first publication rights granted to the journal.

This is an open-access article distributed under the terms and conditions of the Creative Commons Attribution license (http://creativecommons.org/licenses/by/3.0/). 